This item was submitted to Loughborough's Research Repository by the author.

Items in Figshare are protected by copyright, with all rights reserved, unless otherwise indicated.

\title{
Cost-effective parabolic trough foundations for concentrated solar power plants
}

PLEASE CITE THE PUBLISHED VERSION

PUBLISHER

EPPM 2012

VERSION

AM (Accepted Manuscript)

\section{PUBLISHER STATEMENT}

This work is made available according to the conditions of the Creative Commons Attribution-NonCommercialNoDerivatives 4.0 International (CC BY-NC-ND 4.0) licence. Full details of this licence are available at: https://creativecommons.org/licenses/by-nc-nd/4.0/

\section{LICENCE}

CC BY-NC-ND 4.0

\section{REPOSITORY RECORD}

Dallyn, Paul A., Ashraf El-Hamalawi, and Alessandro Palmeri. 2019. "Cost-effective Parabolic Trough Foundations for Concentrated Solar Power Plants”. figshare. https://hdl.handle.net/2134/16299. 


\title{
COST-EFFECTIVE PARABOLIC TROUGH FOUNDATIONS FOR CONCENTRATED SOLAR POWER PLANTS
}

\author{
Paul Dallyn, Ashraf El-Hamalawi and Alessandro Palmeri
}

\begin{abstract}
As part of the continuing requirement for a broad sustainable energy mix, substantial investment is being currently made into renewable energy, including concentrated solar power (CSP). To improve the financial viability of this under-developed technology, research into optimising design is underway in order to reduce the large capital costs associated with CSP plants. At present around $30 \%$ of capital costs of a $50 \mathrm{MW}$ farm are in the solar field (Vallentine et al., 2009), due to the large number of solar collector assemblies (SCAs) required, and therefore there is a large potential to reduce the overall cost by optimising the design of the SCAs and their foundations.

The challenge arises in reducing material and weight, and in simplifying manufacture and assembly, while maintaining the structural rigidity, as the efficiency of the collectors is highly dependent on the optical accuracy. This can be potentially compromised by the wind loading, which is predicted to be the most significant source of optical error (Kolb and Diver, 2008), particularly for flexible systems. A literature review has highlighted that considerable effort has been put into optimising SCA design, but the foundations have been neglected. As well as this there is limited understanding of the loads experienced by the foundations of SCAs.

This paper will present the current level of understanding of SCA loading and how this knowledge can be used to derive the variation in foundation design across the solar field and therefore allow optimisation of foundation design, highlighting potential capital savings that can be made in a typical 50 MW CSP plant.
\end{abstract}

\section{Key words}

Concentrated Solar Power, Foundations, Optimisation, Parabolic Trough

\section{Introduction}

There are four main commercial types of concentrating solar power (CSP) systems that use the Sun's energy as a heat source through concentrating the sunlight onto solar receivers. The four types are parabolic trough, dish/engine, linear Fresnel reflector and power tower, as shown in Fig. 1, with a comparison given in Table 1.

Focus will be on parabolic trough foundations due to the technology being the most mature of the CSP technologies, with its commercial introduction in 1984 with SEGS I in California, and therefore has undergone the most commercial development in order to optimise the technology and reduce the overall cost of energy (Price et al., 2010).

Parabolic trough systems consist of parallel rows of troughs that have single axis tracking of the sun. They are curved in one axis to focus the Sun's light onto an absorber tube that contains heat transfer fluid. This transfers heat via an exchanger to form steam to drive a conventional steam turbine power generation system. Parabolic troughs account for the largest share of the current CSP market and are the most mature technology 
(Kearney, 2007). They are around $14 \%$ efficient in terms of solar radiation to net electricity output (Richter, 2009).
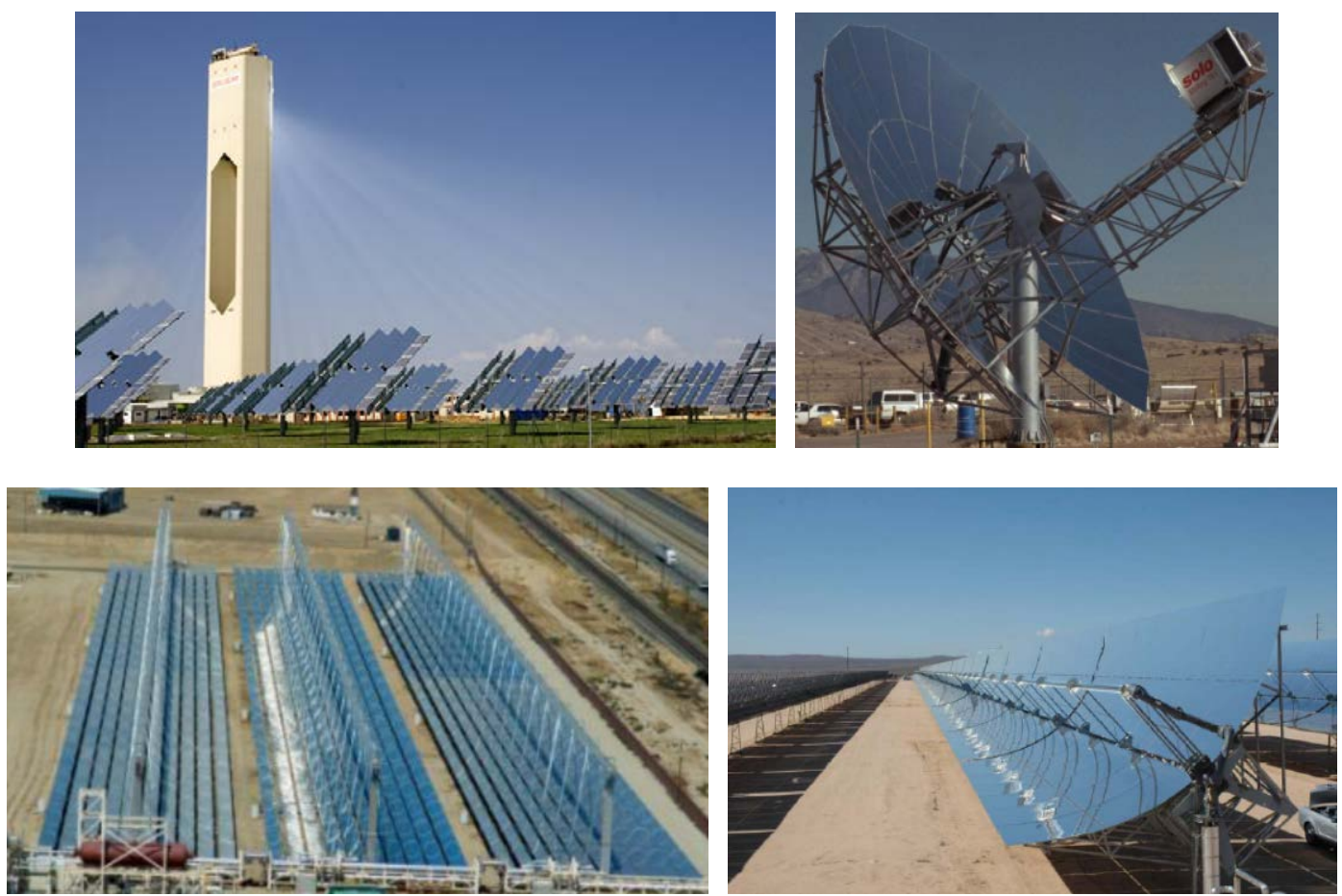

Figure 1: Four main commercial types of CSP plants: Abengoa Solar's PS10 power tower, Seville, Spain (Top left) (Abengoa Solar, a, 2010); Flagsol parabolic troughs at Kramer Junction (SEGS V), California, USA (Bottom right) (Kearney, 2007);Sandia 10-kWe dish/String system (Top right) (Kearney, 2007); Linear Fresnel Reflectors at Kimberlina Solar power station, California, USA (Bottom left) (Areva Solar, 2010).

Site selection and ground works play a key role in the parabolic site as the site must preferably have less than $1 \%$ gradient to minimise shadowing (Abengoa Solar, b, 2010). For $50 \mathrm{MW}$ of power generation a site of around 240 acres and 620 collectors is required, based on 2,000 $\mathrm{kWh} / \mathrm{m}^{2} / \mathrm{yr}$. Foundation types commonly used include mini piles, concrete slabs and concrete caissons. Extensive ground works are normally required to ensure the $1 \%$ gradient.

Table 1. Comparison of CSP Technologies

\begin{tabular}{ccccc}
\hline Technology & Efficiency (\%) & $\begin{array}{c}\text { Ground } \\
\text { Works }\end{array}$ & $\begin{array}{c}\text { 50MW Plant } \\
\text { Area (Acres) }\end{array}$ & $\begin{array}{c}\text { Capital } \\
\text { Cost }\end{array}$ \\
\hline $\begin{array}{c}\text { Power Tower } \\
\text { Parabolic Trough }\end{array}$ & 17 & Intermediate & 590 & Low \\
Dish / Engine & 14 & Extensive & 240 & Low \\
Linear Fresnel Reflector & 11 & Minimal & 500 & High \\
\hline
\end{tabular}

Research into optimising design is underway in order to reduce the large capital costs associated with this underdeveloped technology. Currently 31-35 \% of capital costs of a 
50 MW farm are in the solar field (Vallentine et al., 2009), due to the large number of solar collector assemblies (SCAs) required. This provides a huge potential to reduce the overall cost by optimising the design of the SCAs and foundations. The challenge arises in reducing material, weight, simplifying manufacture, and assembly while maintaining structural rigidity, as efficiency of the collectors is highly dependent on the optical accuracy (Kolb and Diver, 2008). The major factor that influences the structural design of the SCA is wind and therefore a thorough understanding of its behaviour across the expanse of the solar field is important. The SCAs must be able to withstand the wind loading imposed on them while still maintaining their optical accuracy, as wind thrust is predicted by the Eurotrough consortium to be the most significant optical error source.

It has been shown that there is a considerable shielding effect by the first row of SCAs, (Naeeni and Yaghoubi, 2007; Holze et al., 2010 and Hosoya et al., 2008). The foundation design will thus vary according to the field position of the SCAs with the outer foundations being significantly larger in order to accommodate the higher wind loads, which generate larger pitching moments to the foundations. Differential settlement of foundations may also have an effect on optical efficiency over the design life of the plant and so there is a need for development of suitable cost-efficient foundation designs for various soil types and load conditions.

In order for a particular foundation type to be chosen and optimised, an understanding of the complex loading conditions seen by the parabolic trough is required. It has been found that limited work has been undertaken to obtain a clear understanding of the interaction of the troughs within an array and even less work to validate Computational Fluid Dynamic (CFD) models and wind tunnel tests with full scale testing. The most extensive research to date has been carried out by the National Renewable Energy Laboratory (NREL) in the United States of America (Hosoya et al., 2008) and this will form the basis for load calculations. From this estimate of loads, a comparison can be made between locations within the solar field and foundation types typically used for typical conditions of a solar plant found in a semi arid area. Currently foundation solutions are not optimised for their location within the solar array and therefore the force experienced during operation. Through a detailed understanding of the variance in loads experienced, depending on their location with the field, by the SCAs it can be shown that considerable savings can be made on the capital cost of foundations in comparison to foundation designs that are currently being used within industry.

The paper will therefore summarise the background to the loading conditions and foundations currently used in industry before presenting the results of a design comparison between the optimized design based on the location specific loading and designs currently used in industry designs highlighting the potential capital savings that can be made.

\section{Wind Loading}

One of the major structural design considerations in developing solar collector fields is wind loading. Not only must the collector be able to sustain maximum loads, but it must be able to operate accurately during tracking to maintain efficiency. Therefore an understanding of the wind behaviour across the solar field is essential.

The wind loading will be affected by the following factors;

- Collector shape,

- Collector height above ground,

- Collector pitch angle,

- Number and arrangements of collectors in an array, 
- Wind direction.
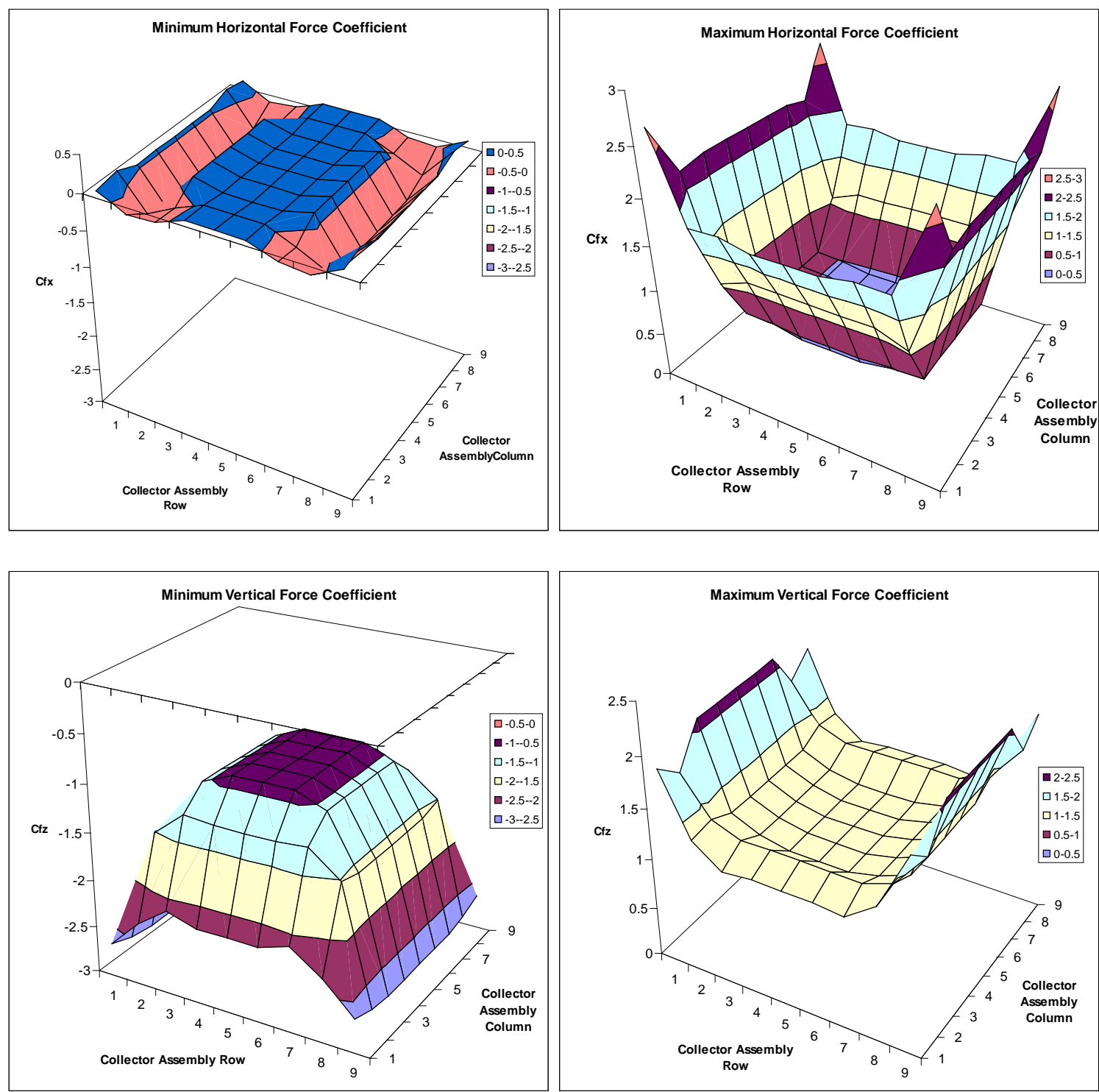

Figure 2. Spatial variance of horizontal and vertical force coefficients

Research into wind loading by Naeeni and Yaghoubi (2007) concluded that the pressure field is very low at 15 - 20 times the collector aperture length from the collector assembly. Therefore the wind force reduces significantly on subsequent collectors. This is confirmed by Holze et al. (2010) who using scale models in wind tunnels to calibrate their numerical simulation results, found that on rows 2 to 10 , a decrease of $40 \%$ and $70 \%$ for maximum moments and loads respectively was observed. They noted that change in the overall loads occurs at the 5th row from the upwind edge of the array field. The mean loads tend to decrease continually through to the 5th row where they reach their minimum, regardless of the pitch angle, but in some instances the dynamic loads are amplified within the interior of the field, resulting in negligible reduction in the effective peak design load. This is due to the downstream turbulence caused by the collector row in front; it was noted as being especially true when the collectors are at a pitch angle of -60 degrees. This dynamic effect was also noted by Hosoya et al. (2008) in wind tunnel findings and is particularly prominent in the horizontal force on the $2^{\text {nd }}$ row of collectors which experience 
upwind forces greater than anywhere else on the field. This can be seen in Fig. 2 which is derived from raw data presented in Hosoya et al. (2008).

Eupfet and Greyer (2001) concluded that $95 \%$ of the solar collector assemblies are within the shadowed inner field, $2.5 \%$ are in the transient area and $2.5 \%$ on the high load outer edge and therefore three different foundation structures are necessary to ensure efficient field design.

Hosoya et al. (2008) reported on their results from wind tunnel testing of parabolic solar collectors. Within this report, detailed data was included on force and moment coefficients for various collector locations within a field array for different prominent wind orientations and throughout the operational range of collector pitches. From this, a good understanding of the varying forces and moments seen across the field for various operating conditions can be developed. Analysis of this coefficient data reported shows that the peak horizontal force and moment coefficients are seen on the corner assemblies of the field, with the horizontal force component being just over six times the value of the inner field. There is a dramatic drop in the horizontal peak coefficient with the $2^{\text {nd }}$ row of central columns of collectors only having $23 \%$ of the value of the $1^{\text {st }}$ row. The spatial variance of peak horizontal and vertical force coefficients can be seen in Fig. 2, based on worst case wind direction (yaw of $30^{\circ}$ to first or last row of field). The results also indicate that there is a considerable drop in force and moment coefficients from the $1^{\text {st }}$ outer row / column to the $4^{\text {th }}$ row / column. With the rest of the inner field experiencing very little variation from the $4^{\text {th }}$ row / column inwards, but the $2^{\text {nd }}$ row can experience larger negative horizontal forces. Given the detail of Hosoya et al. (2008) results and the general agreement with other findings, their data has used as the input for the wind loading which has been used for the design comparison and optimisation.

\section{Foundations}

Based on reviews of current solar farms in operation it can be seen that there are a variety of foundation types in use. There is not only variation in design concepts from plant to plant, but also within the site to cater for the varying wind loading across the site, with perimeter foundations and inner field foundations. From the research undertaken, four main commercially used foundations have been found.

\section{Reinforced Slab}

This is one of the more widely used foundation types seen at various sites across the world including Solnova 1. They only require simple excavation of a cuboid pit using standard and widely available excavators. Metal jigs are then used to locate the anchoring bolts accurately to ensure correct position and angle while the concrete is poured and sets.

Investigation of safety factors on site specifications of foundation design suggests that the slab design can be optimised, with a subsequent reduction in spoil removed and concrete volume used. Due to sliding having the lowest factor of safety, optimisation is likely to be achieved by reducing the length of the slab whilst increasing the width or depth to maintain the bearing and overturning capacity while increasing the sliding capacity. Optimisation will be discussed later in the comparison section.

\section{Mini Pile}

This is one of the simplest foundation types requiring minimal ground preparation and very little to no soil removal. It has demonstrated experience in the use of underpinning of buildings and for Arizona Western College Solar Project, Metal Foundation Industries 
(2012). The mini pile design consists of steel piles driven into the ground in a rectangular grouping. Anchoring points are then grouted into the centre of the piles or an integrated connection on the pile top is used to fix and align the SCA.

Calculations carried out indicate that at a typical site depth there is insufficient friction to ensure uplift does not occur under the action of the vertical wind force and pitching moment for all load cases. Uplift is therefore the most critical failure mode for mini-pile design.

Based on API conditions, the pile separation for the inner field mini pile design as used on site is within the lower boundary of influence between piles, taken as 3-5 $D$, which should be avoided for friction piles. Therefore more in depth soil to pile interaction using finite element analysis is required to accurately calculate pile capacities.

\section{Pair of Drilled Caissons}

These foundations consist of two reinforced concrete caissons each containing two of the four SCA locating bolts. Two boreholes are excavated via a specialist rotary boring excavator; a metal jig is used to align the anchoring points across the pair of caissons and to hold the reinforcement in place while concrete is poured. As with the pile design, varying the foundation footprint to accommodate varying loads has the advantage of fixing the price of the foundation throughout the field due to material and installation cost being independent of loading conditions associated with location within the field.

The calculations assume there is no interaction between the adjacent caissons. Bowles (1988) states it is safe to make this assumption as long as caisson separation is greater than or equal to two diameters for no interaction to be considered to occur.

\section{Single Drilled Caisson}

This type of foundation concept is used greatly in the USA, for example commercial development at Nevada Solar One, USA. Increase in wind loading can be catered for by increasing the size of the caisson or by using slabs on the outer edge of the fields. Installation only requires one rotary bore for each foundation, reducing excavation time per foundation as repositioning of equipment is not required, unlike with the twin caisson design. Based on the foundation calculations, the critical failure mode was overturning which was therefore the driving criterion for design optimisation.

\section{Design Methodology}

\section{Loading}

Based on the extensive force and moment coefficients of Hosoya et al., (2008) the design loads for the foundations were calculated based on the following equations (Hosoya et al., 2008)

Horizontal Force, $F_{x}$

Vertical Force, $F_{z}$

Pitching Moment, $M_{y}$

Where

$$
\begin{aligned}
& F x=q L W C_{f x} \\
& F z=q L W C_{f z} \\
& M y=q L W^{2} C_{m y} \\
& q=1 / 2 \rho U^{2}
\end{aligned}
$$


$q$ is the mean dynamic pressure measured at the collector pivot height of the solar collector, $L$ is the length of the collector, $W$ is the collector surface height, $U$ is the mean wind speed at pivot height and $\rho$ is the density of air.

The mean wind speed at pivot height needs to be obtained from the design wind speed of the solar power plant in line with design codes. Due to limited availability of wind data and associated design codes for the site region, an assumption of wind speed at collector pivot height, $U$ of $33 \mathrm{~m} / \mathrm{s}$ has been used, as this has been the value used for other collector assemblies with similar dimensions (Kearney, 2007). The use of $33 \mathrm{~m} / \mathrm{s}$ is also justified by the chimney basic design wind speed at site of $28.6 \mathrm{~m} / \mathrm{s}$. Calculations have also been carried out with design wind speeds of $4 \mathrm{~m} / \mathrm{s}$ and $14 \mathrm{~m} / \mathrm{s}$. These figures represent typical average site wind speed recorded during 2010 and maximum site wind speed prior to positioning the collector in the stow position during operation of the plant. As a considerable number of commercial plants use a variant of the Eurotrough, the dimensions of these troughs (Table 2) were used to determine the foundation loads.

It is understood that the solar collectors are placed into the stow position when site wind speeds are in excess of $14 \mathrm{~m} / \mathrm{s}$ and so for the calculations when the design wind speeds are greater than $14 \mathrm{~m} / \mathrm{s}$, a stow position of $-90^{\circ}$ has been used. It is noted that during the erection phase, the collectors cannot be placed into the stow position, which raises potential issues with collectors being exposed to significantly higher wind speeds than design conditions anticipate.

Table 2 Dimensions of typical Eurotrough variant (Kearney 2007).

\section{Collector Structure}

Wind load design basis $(\mathrm{m} / \mathrm{s})$

Aperture width (m)

Focal length (m)

Length per collector module (m)

Length per SCA (m)
Torque tube + stamped steel cantilever

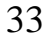

5.76

1.71

12

148.5

Based on these dimensions and the design wind speed, the maximum horizontal and vertical forces, and pitching moments were obtained from equations $1-4$, and then used for the live load conditions on solar collector foundations within the field. Given the experimental setup used by Hosoya et al. (2008), it has been assumed that the forces derived from their coefficients would represent the forces seen at the top of the foundation, i.e. at $0.1 \mathrm{~m}$ above ground level based on a ground clearance typically found on sites. From the findings of the various research into wind force coefficient distributions throughout the field, four main loading conditions were considered to be representative; outer row/column fenced and unfenced (case 1 and 2), $2^{\text {nd }}$ row (case 3), inner field (case 4).

Although most solar plant sites have surrounding wind barriers consisting of heaped spoil embankments, as a way of disposing of excess spoil, they are only of the order $4 \mathrm{~m}$ high and around $7 \mathrm{~m}$ from the outer collectors. It is because of uncertainty in the effect of wind breaks that the load case without the wind barrier has been considered to represent a worst case scenario, but given the correlation of Naeeni and Yaghoubi's and the NREL's findings, the load case with the wind barrier should give a reasonable estimate. There has 
been no study found related to the influence of types of barrier or distance of barrier from the collector to the forces seen by the SCAs.

\section{Foundation Design}

Initial foundation specifications used for the comparison of foundation concepts are based on typical dimensions found on power plant sites. Typically there are two variations of each foundation design, one for the central field and the other for intermediate collectors. It is assumed that based on a worst case, the outer foundations are the same as the intermediate ones. For each of the locations, the maximum horizontal force was selected for all the operating pitches and wind directions, the corresponding vertical force and moment were then used.

Site specific soil characteristics were unavailable and so reference characteristics based on a compacted dry sandy soil similar to ground conditions at a typical semi arid site were used in order to enable a comparison between the designs. From this information, basic bearing, uplift and overturning calculations were carried out for ultimate limit state for the four load cases on each of the foundation types according to the British Standards.

The calculations do not factor the loads or capacities in order for an overall factor of safety to be determined and then used for comparison of suitability of the foundation to four loading conditions. A factor of safety of 2 has been chosen as a minimum acceptable design criterion. Self weight of the collectors has not been incorporated in the design calculations due to the unavailability of SCA weight data. The introduction of self weight into the calculations would be beneficial and result in a reduction of uplift and overturning moments for the foundations.

\section{Optimisation}

A comparison of the four different types of foundations based on the assumption of $33 \mathrm{~m} / \mathrm{s}$ design wind speed, the stow position of $-90^{\circ}$ and the soil characteristics mentioned previously can be seen in Table 3. Initial sizing is based on typical site design specifications, the $2^{\text {nd }}$ sizing represents the required foundation to meet a safety factor of 2 based on increasing depths if an insufficient safety factor was achieved based on the site specifications. The $3^{\text {rd }}$ is the fully optimised foundation specifications that produce the minimum volume of materials required and spoil produced while still achieving a sufficient factor of safety for the failure modes. Based on these quantities costs has been produced that take account of materials, labour and equipment. The costs do not include associated costs such as mobilisation/demobilisation, welfare, access routes, drainage costs etc. These costs have been derived from rates published in SPON's Civil Engineering and Highway Works Price Book by Langdon (2010), so it should be noted that although this allows for a good financial estimate, labour rates for the majority of countries where large solar projects are being installed tend to be cheaper and so more labour intensive foundations could perform better in the comparison. The costing also does not take account for the variation in SCA support structure that maybe required for the different foundation types.

In terms of optimisation of the existing foundations consideration of structural integrity becomes important, for example the caisson design, optimization suggests that the diameter could be reduced. However, reducing the diameter of the caisson reduces the self weight so the factor of safety for uplift becomes important. As the slenderness increases, the structural integrity of the caisson will become important and will need verifying due to limit state design parameters. 
Table 3 Optimisation of Typical CSA Foundations

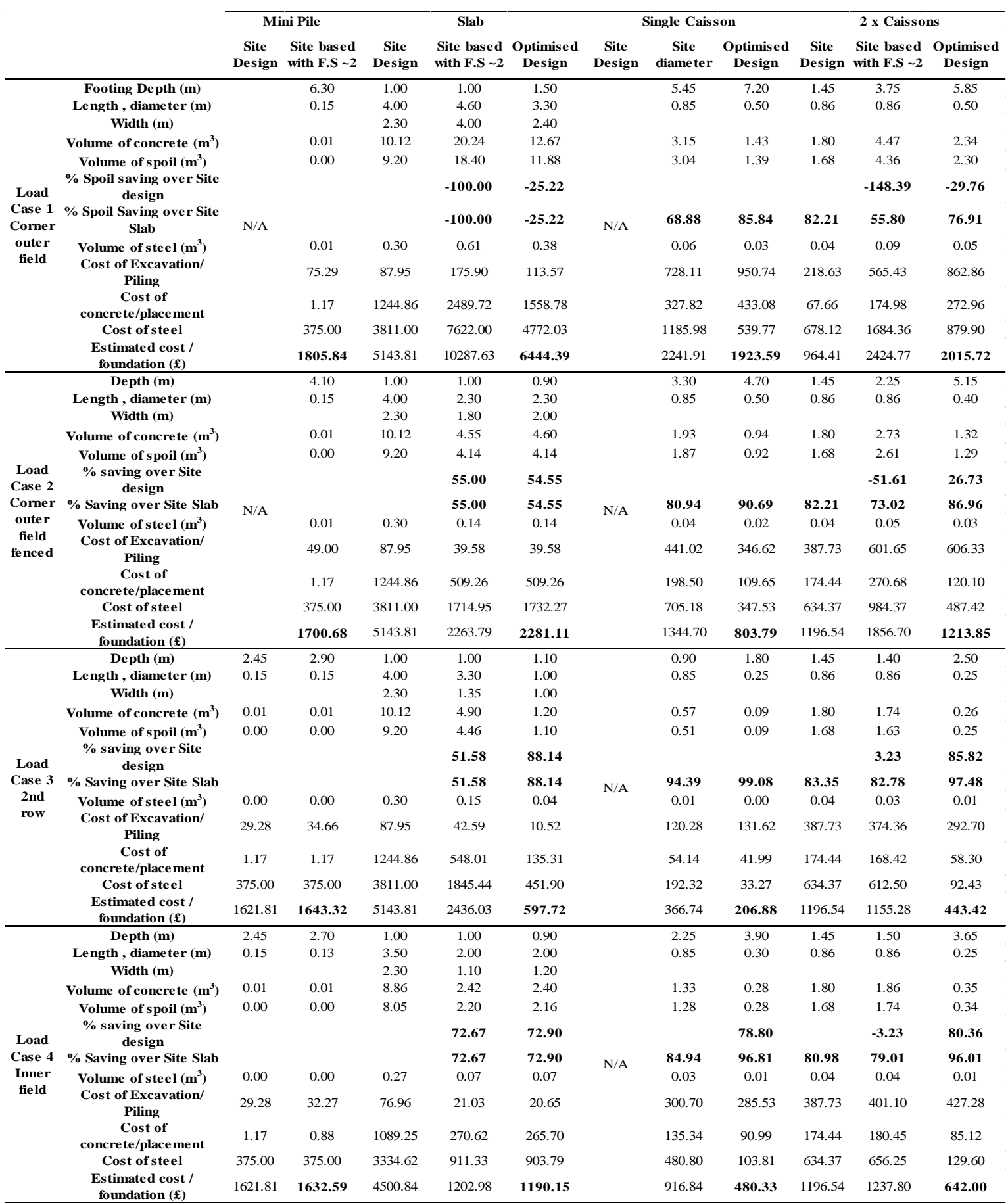

For the purposes of this design, basic limit state design principles have been adhered to and the concrete member length to lateral diameter has been limited to less than 15 to avoid buckling. If the foundation diameter $<0.75 \mathrm{~m}$ and $<1 / 4$ of the depth of the structure, it has been modeled as a pile. Classification of caissons and slabs are follows; a caisson is defined by a ratio of $1<d: B<4$ and a pad / slab foundation defined by $d: B<1$, where $d$ is the depth and $B$ is the breadth of the foundation, Institute of Structural Engineers (2002).

By moving to a pile design it is possible that borehole excavations may require support through the introduction of a casing or slurry e.g. bentonite. If the use of slurry is required to support the excavation in addition to initial spoil there will also be slurry waste to 
dispose of. The majority of materials currently used as slurry must be disposed of at suitable, licensed waste facilities and cannot be re-used on site, this adds additional cost, especially given the remoteness of typical sites. Initial design considerations indicate that potential additional costs and time that may be incurred, due to depth of excavation and the requirement to use stabilising slurry for excavations, may invalidate any savings achieved through design optimisation. The use of driven piles may prove more cost-effective than bored piles and should be given further consideration at concept design stage.

In terms of material volume, it can be seen from table 3 that the caisson design represents the optimum design in terms of minimisation of concrete and spoil. In terms of an overall cost estimate per foundation the caisson design is also the cheapest of the four options for all cases apart from the unfenced outer location. For this location, the two caisson designs offer the most cost-effective solution due to the horizontal loads being too high for a single caisson to withstand structurally without becoming very large in diameter. It should be noted that the stability of the bore hole was not considered at this stage due to the uncertainty of soil conditions.

A comparison between the designs found on the case study site, with dimensions adequate enough to meet a minimum factor of safety of 2, indicates that the use of mini piles is the most cost-effective solution in most of the load conditions considered, apart from the inner field where a small slab foundation could offer a $7.5 \%$ saving over the mini piles.

The basic optimisation that has been undertaken shows that significant cost savings could be made for all locations throughout the field and in some locations such as the $2^{\text {nd }}$ row optimisation could lead to savings of up to $60 \%$ over the designs currently being used on typical sites. For a typical $50 \mathrm{MW}$ site this potential saving for the three different foundation locations could represent a total saving of around $£ 1.8 \mathrm{~m}$ for the foundation works over the typical site foundation design currently used based on providing the same factor of safety, the assumptions stated earlier and 2 foundations per collector. Given that solar projects are only getting larger in scale, the potential for financial savings in the solar field would only increase further in the future.

A factor that has not been considered in great detail is the effect of foundation settlement which will affect collector efficiency, as this is highly dependent on line and level of the collector assembly. Misalignments of the collectors can significantly reduce output efficiency with minor adjustment to correct this adding to maintenance costs. Settlement of foundations and differential settlements between foundation groups could therefore be critical in achieving overall plant performance. As the majority of solar projects are sited on granular soils there is unlikely to be foundation settlement issues (Bowles, 1988) with the majority of ground settlement occurring within 7 days of the collector being placed onto the structural support frame and foundation. Final line and level checks of the collectors are often not carried out immediately and as such by the time final checks are carried out all settlement will have taken place. Developments on cohesive fine grained soils are at increased risk of suffering from settlement issues due to the majority of settlement occurring over an extended period of time. In the case of solar collectors, this translates to a requirement to check line and level of the collectors at regular intervals to correct any misalignments and maintain efficiency if differential settlement occurs. In the case of slab foundations, it is also necessary to check for differential settlements resulting from foundation rotation at the edge of the foundations due to high horizontal wind load. Initial calculations indicate that differential settlement of the outer perimeter slab foundations is not of concern, but if a lifetime cost analysis is to be performed, more detailed investigation will be required to determine the frequency of alignment checks and adjustment. 
Another potential for improvement is the accuracy of the design wind loads assumed for calculation purposes as this was based on limited design data supplied by site operators and limits used throughout the industry. In order to gain a more accurate assessment of the likely risk of extreme gusts of different magnitudes at site, it is recommended that local wind speed measurement data is collected from site for at least one complete year, and at a representative location and height above ground level. This data could then be analysed and correlated against a suitable local meteorological station for which long-term (up to 20-year) data is available, in order to develop a long-term wind resource distribution at the site to provide a more accurate estimate of the probability of critical wind speeds being exceeded at the site. Significant improvements could also be made to the derived loads through the production of a CFD model calibrated to full scale site experimental results as there is no evidence of full scale testing to date.

Investigation of the suitability of a stow angle of $-90^{\circ}$ indicates that $-100^{\circ}$ produces minimum forces, with the magnitude difference between $-90^{\circ}$ and $-100^{\circ}$ for the mini pile design indicating that wind speeds of up to $26.5 \mathrm{~m} / \mathrm{s}$ can be accommodated at $-100^{\circ}$ compared to $23 \mathrm{~m} / \mathrm{s}$ at the $-90^{\circ}$ stow position.

\section{Conclusions}

This paper has reviewed currently available data on solar collector foundations and has presented an initial assessment of the foundation designs at a typical example site. There is relatively limited information available on foundation design for solar collectors as CSP technology remains in the early stages of development. The literature review has highlighted that little research has been carried out to assess suitable and cost-effective foundation types such as the four main types of foundations currently in use, i.e. slab base, pair of drilled caissons, single caisson and mini pile/pile. It suggests that the types of foundations used as examples of site foundations are typical of those adopted for CSP plants currently being developed. There is limited practical experience on the performance of foundations in the field, although there are no reports of failures or extensive remedial works required.

Wind loading is the primary design load for consideration, particularly for seismicinactive areas, but there is limited understanding of the variance of wind load across the collector array, given the complex shape and changing position of the collectors throughout the day. As such wind loading has been calculated in this paper from available laboratory data and applied to a typical trough to carry out the foundation design. The assumed design value of the wind speed is based on design parameters adopted in similar sites, and is consistent with the basic wind speed adopted for chimney design at site. The maximum operating wind speed before the stow position is adopted is $14 \mathrm{~m} / \mathrm{s}$ and less than half the design speed.

The results of the analysis of initial typical site designs indicate that the mini-pile design could be susceptible to uplift when site wind speeds are greater than the maximum operating wind speed of $14 \mathrm{~m} / \mathrm{s}$ and the collector is in the stow position, but stow position optimisation could improve the situation.

The caisson design achieves minimum desirable factors of safety for all failure modes at operational wind speeds and therefore can be optimised.

The slab foundation has considerable factors of safety and so considerable optimisation can be achieved on this foundation type.

A financial comparison indicates that a single caisson design could represent the most cost-effective solution for CSP foundations, based on the assumptions made. 
There is limited confidence in using traditional foundation modelling for the uniqueness of parabolic trough collector foundations and there would be considerable benefit to carrying out further, more in depth research into the behaviour of the collectors within the field. It is recommended that any further modelling work is validated through site data collection.

Settlement of foundations is not considered to be an issue, as any potential settlement effects could be addressed at the detailed design stage.

Overall the calculations suggest that foundation design optimisation is possible and significant financial savings can be made in the construction of foundations in the solar field of parabolic trough concentrated solar power projects, with this work indicating a possible saving of around $£ 1.8 \mathrm{~m}$ on a small $50 \mathrm{MW}$ example case study. This saving could be delivered through further modelling work to achieve greater confidence in results and a reduction of allowable factors of safety to achieve even greater cost savings.

\section{References}

Abengoa Solar, a, 2010. Solucar Platform, PS10 [online]. Available from: www.abengoasolar.com [Accessed 10 November 10]

Abengoa Solar, b, 2010. Concentrating Solar Power- Power Tower and Parabolic Trough. [online]. 10/11/10. Available from: www.abengoasolar.com.

Areva Solar, 2010. Kimberlina CLFR Solar Thermal Power Plant. [online]. Available from: www.svpvs.org [Accessed 10 November 10]

Bowles, J., 1988. Foundation, Analysis and Design, $4^{\text {th }}$ Edition. McGraw-Hill International.

Eupfet, E. and Greyer, M., 2001. Eurotrough Design Issues, Prototyping and Testing at PSA., ASME Solar Energy Conference 2001.

Holze, C., Brucks, A. and Henke, R., 2010. Numerical and Experimental Optimization of Innovative parabolic Trough Collector Field Configurations. SolarPACES 2010.

Hosoya, N., Peterka, J., Gee, R., and Keamey, D., 2008. Wind Tunnel Tests of Parabolic Trough Solar Collectors, National Renewable Energy Laboratory Report.

Institute of Structural Engineers, 2002. Manual for the Design of Reinforced Concrete Building Structures. $2^{\text {nd }}$ Edition. London: The Institute of Structural Engineers.

Kearney, D.W., 2007. Parabolic Trough Collector Overview, Parabolic Trough Workshop National Renewable Energy Laboratory.

Kolb, G. and Diver, R., 2008. Conceptual Design of an Advanced Trough Utilising a Molten Salt Working Fluid, SolarPACES 12,Las Vegas.2008.

Langdon, D., 2010. SPON'S - Civil Engineering and Highway Works Price Book 2010. $24^{\text {th }}$ Edition. Abingdon: Spon Press.

Metal Foundations Industries, 2012. Metal Foundations Projects. [online]. 30/07/12. Available from: www.metalfoundationscoup.com.

Naeeni, N. and Yaghoubi, M., 2007. Analysis of Wind Flow Around a Parabolic Collector (1) Fluid Flow, Renewable Energy 32, pp1898-1916.

Price, H., Lupfert, E., Kearney, D. and Gee, R. (2002), Advances in Parabolic Trough Solar Power Technology. Journal of Solar Energy Engineering, Vol. 145, pp. 140-145.

Richter, C., Teske, S. and Short, R., 2009. Concentrating Solar Power- Global Outlook, SolarPACES, 2009.

Vallentine, D. And Viebahn, P., 2009. Okonomische Chachen fur die Deutcshe Industrie Result irrend aus einer Weltweiten Verbreitung von CSP Technologien, Wuppertal Institut fur kilme. 